\title{
Alleviation of Ultraviolet B-Induced Photoaging by 7-MEGATM 500 in Hairless Mouse Skin
}

\author{
Kyo-Hyun Park', JiYeon Kim', Suryun Jung ${ }^{1}$, Kyung-hwa Sung ${ }^{2}$, Yeon-Kyoung Son ${ }^{3}$, Jung Min Bae ${ }^{4}$ \\ and Bae-Hwan Kim ${ }^{1}$ \\ ${ }^{1}$ Department of Public Health, Keimyung University, Daegu, Korea \\ ${ }^{2}$ Environmental Health Services Center, Daegu Catholic University, Daegu, Korea \\ ${ }^{3} R \& D$ Team, Food \& Supplement Health Claims, Vitech, Jeonju, Korea \\ ${ }^{4}$ Department of Technical Assistance, Agency for Korea National Food Cluster (AnFC), Iksan, Korea
}

\begin{abstract}
The purpose of this study was to investigate the effect of 7-MEGA ${ }^{\mathrm{TM}} 500$ on the improvement of skin aging in an UVB-induced photo-aging model of hairless mice. The dorsal skin of hairless mice was exposed to UVB three times a week for 12 weeks to induce skin wrinkle. After inducing the wrinkle, 7-MEGA ${ }^{\mathrm{TM}} 500$ was orally administered once a day for 4 weeks. Skin thickness, skin barrier function, and wrinkle indicators were improved by treatment with 7-MEGA ${ }^{\mathrm{TM}}$ 500. Both gene and protein expression levels of MMP-3 and c-Jun in skin were significantly decreased by 7-MEGA ${ }^{\mathrm{TM}} 500$. Therefore, the intake of 7-MEGA ${ }^{\mathrm{TM}} 500$ is thought to have a positive effect on the improvement of skin aging, although further studies are needed.
\end{abstract}

Key words: 7-MEGA ${ }^{\mathrm{TM}}$ 500, Photoaging, Hairless mice, c-Jun, MMP-3

\section{INTRODUCTION}

Ultraviolet (UV) is abundant in the environment. It is the most important risk factor for skin cancer. It not only increases epidermal thickness, but also increases wrinkle formation (1). UV irradiation also induces the synthesis of matrix metalloproteinases (MMPs) and decrease of collagen synthesis (2).

Collagen degradation is closely related to the presence of MMPs that are mainly secreted by epidermal keratinocytes and dermal fibroblasts. MMPs are usually expressed at low levels in unstimulated cells or normal skin tissues. However, they can be induced by various extracellular stimuli, including cytokines, growth factors, and UV radiation. Up-regulation of MMPs can also be induced by

Correspondence to: Bae-Hwan Kim, Department of Public Health, Keimyung University, 1095 Dalgubeoldaero, Dalseo-gu, Daegu 42601, Korea

E-mail: kim9399@kmu.ac.kr

This is an Open-Access article distributed under the terms of the Creative Commons Attribution Non-Commercial License (http:// creativecommons.org/licenses/by-nc/3.0) which permits unrestricted non-commercial use, distribution, and reproduction in any medium, provided the original work is properly cited. even a minimal dose of UV (3). After chronical exposure to UV-irradiation, mouse skin shows epidermal hyperplasia, skin wrinkles, and significant increase of several MMPs, including stromelysin-1 (MMP-3), metalloelastase (MMP12), and collagenase (MMP-1) (4).

It has been shown that omega polyunsaturated fatty acids (PUFAs) possess anti-oxidative (5), anti-inflammatory (6), neuroprotective (7), and chemopreventive (8) effects. Omega-6 and -9 have been linked to obesity prevention (9) and anti-inflammation (10). Recent studies have shown that PUFAs can defend a wide range of diseases characterized by increased MMPs activity (11). They can also suppress UV-induced expression of proinflammatory cytokines and MMPs in skin cells in vitro or skin tissues in vivo $(1,4)$. Moreover, it has been reported tht palmitoleic acid (omega-7) and gamma-linolenic acid (omega-6) can affect skin regeneration and repair (12). However, there have been few reports on omega-7 compared to other omega fatty acids. Omega-7, also known as palmitoleic acid (16:1, Cis-9-hexadecenoic acid), is a monounsaturated fatty acid that is found in fish and plants such as macadamias, cold water fish, and sea buckthorn berries (13).

It has been previously shown that omega- 3 and omega- 6 
act as inhibitors of MMPs (11), and 7-MEGA ${ }^{\mathrm{TM}} 500$ (more than $50 \%$ of palmitoleic acid containing fish oil, omega-7) can show the effects of anti-oxidant and anti-inflammation in vitro (14). However, in vivo information on its effects on skin has been insufficient. Therefore, the aim of this study was to investigate the effect of $7-\mathrm{MEGA}^{\mathrm{TM}} 500$ by observing expression levels of MMP-3 and c-Jun on skin of mouse.

\section{MATERIALS AND METHODS}

Preparation of 7-MEGA ${ }^{T M}$ 500. $7-\mathrm{MEGA}^{\mathrm{TM}} 500$ was obtained from Organic Technologies (OH, USA). Pollock was collected from Alaskan Bering Sea and 7-MEGA ${ }^{\mathrm{TM}}$ 500 containing palmitoleic acid $(>500 \mathrm{mg} / \mathrm{g})$ was prepared (Table 1). 7-MEGA ${ }^{\mathrm{TM}} 500$ was administered by volume of $10 \mathrm{~mL} / \mathrm{kg}$ after dissolving a defined concentration of each group in $30 \% \mathrm{EtOH}$.

Animals. Male HR-1 hairless mice (5-week old, 18$20 \mathrm{~g}$ ) were purchased from Orient Bio (Seongnam, Korea). After acclimation for one week, they were randomly assigned to five groups (Table 2). The animal room was maintained at a temperature of $22 \pm 3^{\circ} \mathrm{C}$ with relative humidity of $50 \pm 10 \%$ and 12 -hr light/12-hr dark cycle per day. They were provided free access to feed (Purina, Korea) and water ad libitum during the experiment period. All experimental protocols were approved by the Institutional Animal Care and Use Committee (IACUC) of Keimyung University, South Korea (permit number: KM2017-005).

Design of skin photoaging model. The dorsal skin of hairless mice was exposed to UVB three times a week. The irradiation dose was increased weekly by 1 MED (1 $\mathrm{MED}=130 \mathrm{~mJ} / \mathrm{cm}^{2}$ ) to 4 MED. It was then maintained at

Table 1. The main ingredients of 7-MEGA ${ }^{\mathrm{TM}} 500$

\begin{tabular}{llcc}
\hline \hline $\begin{array}{c}\text { Molecular } \\
\text { formula }\end{array}$ & \multicolumn{1}{c}{ Name } & $\mathrm{mg} / \mathrm{g}$ & $\%$ \\
\hline C14:0 & Myristic acid & $4.4 \pm 5.0$ & 0.04 \\
C16:0 & Palmitic acid & $257.3 \pm 27.1$ & 25.7 \\
C16:1n-7 & Palmitoleic acid & $535.6 \pm 10.9$ & 53.5 \\
C20:5 & Eicosapentaenoic acid (EPA) & $5.6 \pm 6.4$ & 0.06 \\
\hline
\end{tabular}

4 MED until 12 weeks. After skin photoaging induction (1-8 weeks), the test material or vehicle was orally administered $(10 \mathrm{~mL} / \mathrm{kg}$, once a day) for 4 weeks.

Determination of wrinkle grade. To determine the severity of wrinkling, each hairless mouse was anesthetized and the UVB exposed dorsal skin (wrinkle formation area) was photographed. The severity of wrinkling was measured using Bissett's visual wrinkle scale. Skin impressions (replicas) were prepared by applying Repliflo Cartridge Kit (CuDerm Corp., Dallas, TX, USA) to dorsal skin of each mousee. Replicas were analyzed using a skin visioline VL650 (CK Electronics GmbH, Cologne, Germany).

Measurement of skin barrier function. Transepidermal water loss (TEWL) and stratum corneum (SC) water content were assessed under standardized conditions (external temperature $23 \pm 3^{\circ} \mathrm{C}$ and $50 \pm 10 \% \mathrm{RH}$ ) using a Tewameter (Courage-Khazaka Electronic GmbH, Cologne, Germany) and a Corneometer (Courage-Khazaka Electronic $\mathrm{GmbH}$ ) apparatus, respectively.

Measurement of skin thickness. Skin thickness was measured using a digimatic micrometer (Mitutoyo Co. Ltd., Tokyo, Japan) once a week. The dorsal skin of each mouse was pulled up from the neck to the bottom of the body by hand and the skin fold thickness was measured between the neck and hips.

Histological observation. Dorsal skin from autopsy was fixed in $10 \%$ formalin for $24 \mathrm{hr}$ and embedded in paraffin with common process. Embedded tissue was cut into $4 \mu \mathrm{m}$-thick sections and stained with hematoxylin and eosin (H\&E). Changes of skin tissue such as epidermal thickness and inflammatory cell infiltration were observed under an optical microscope.

RNA isolation and RT-PCR. Total RNA was isolated from dorsal skin of mouse using TRIzol reagent (Life Technologies Inc., Rockville, MD, USA) according to the manufacturer's protocol. Total RNA was used to synthesize cDNA with an iScript cDNA Synthesis Kit (Bio-Rad Laboratories, Hercules, CA, USA). PCR amplification of cDNA $(4 \mu \mathrm{L})$ was performed with PCR premix (SolGent, Daejeon, Korea) and primer pairs (Bionics, Seoul, Korea;

Table 2. Experimental groups

\begin{tabular}{cclc}
\hline \hline Groups & Induction of skin photoaging & \multicolumn{1}{c}{ Test compound } & No. of mice \\
\hline Normal Control (NC) & - & Distilled water $(\mathrm{DW})$ & 7 \\
Vehicle Control (VC) & + & $30 \%$ EtOH & 7 \\
Experimental 1 (E1) & + & 7-MEGA & 7 \\
Experimental 2 (E2) & + & 7-MEGA $(200 \mathrm{mg} / \mathrm{kg})$ & 7 \\
Experimental 3 (E3) & + & 7-MEGA & $(100 \mathrm{mg} / \mathrm{kg})$ \\
\hline
\end{tabular}


Table 3. Primer sequences for RT-PCR

\begin{tabular}{clcc}
\hline \hline & & Primer sequences $^{1)}$ & ${\text { Amplicon size }(\mathrm{bp})^{2)}}^{2}$ \\
\hline \multirow{2}{*}{ GAPDH } & Sense & 5'-AACTTTGGCATTGTGGAAGG-3' & 223 \\
& Antisense & 5'-ACACATTGGGGGTAGGAACA-3' & \multirow{2}{*}{146} \\
\hline \multirow{2}{*}{ c-Jun } & Sense & 5'-TCCCCTATCGACATGGAGTC-3' & \multirow{2}{*}{317} \\
& Antisense & 5'-TTTTGCGCTTTCAAGGTTTT-3' & \\
\hline \multirow{2}{*}{ MMP-3 } & Sense & 5'-CAGGTGTGGTGTTCCTGATG-3' & \\
& Antisense & 5'-GCCTTGGCTGAGTGGTAGAG-3' & \\
\hline
\end{tabular}

${ }^{1)}$ Primer sequences (Bionics, Seoul, Korea).

${ }^{2)} \mathrm{bp}$, basepair.

Table 3). Before PCR amplification, the PCR mixture was denatured at $95^{\circ} \mathrm{C}$ for $2 \mathrm{~min}$. Amplification consisted of 35 cycles of denaturation at $95^{\circ} \mathrm{C}$ for $20 \mathrm{sec}$, annealing at $57^{\circ} \mathrm{C}$ for $40 \mathrm{sec}$, and extension at $72^{\circ} \mathrm{C}$ for $1 \mathrm{~min}$, followed by a final extension at $72^{\circ} \mathrm{C}$ for $5 \mathrm{~min}$. PCR products were separated by $1 \%$ agarose gel electrophoresis and visualized with $6 \mathrm{X}$ loading dye and UV illumination.

Western blot analysis. Mouse dorsal skin sections were homogenized in radioimmunoprecipitation assay buffer (Sigma, USA) containing 1\% protease inhibitor cocktail and phosphatase inhibitor cocktail. The homogenate was centrifuged at $14,000 \mathrm{rpm}$ for $10 \mathrm{~min}$ at $4^{\circ} \mathrm{C}$. The supernatant was collected and protein concentration was estimated by the Bradford protein assay. A $30 \mu \mathrm{L}$ aliquot of protein was separated by $10 \%$ sodium dodecyl sulfatepolyacrylamide gel electrophoresis (SDS-PAGE). Resulting separated proteins were transferred onto nitrocellulose membranes. Membranes were blocked with 5\% skim milk in TBS-T (Tris-Buffered Saline plus $0.05 \%$ Tween 20). The following primary antibodies were used for western blotting: c-Jun, MMP-3, and $\beta$-actin (Santa Cruz Biotechnology, Santa Cruz, CA, USA). Immunoreactive bands were visualized using enhanced chemiluminescence (ECL) detection reagents (Amersham Biosciences, Amersham, UK). Band intensities were measured using ImageJ software

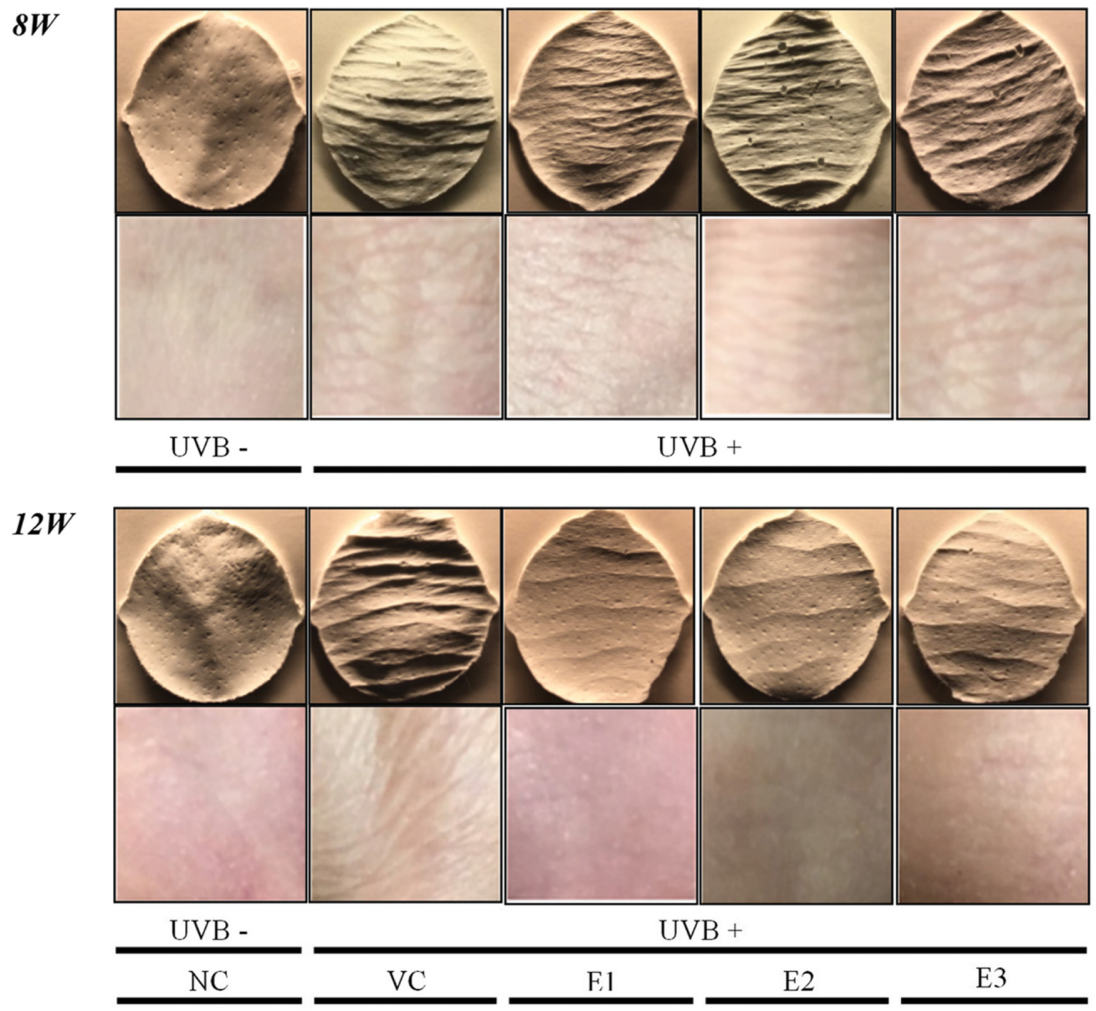

Fig. 1. Replica production and visual wrinkle patterns of skin. $8 \mathrm{w}$ : Before oral administration, $12 \mathrm{w}$ : Four weeks after oral administration. NC: Normal control, VC: Vehicle control, E1: 7-MEGA ${ }^{\mathrm{TM}} 500(200 \mathrm{mg} / \mathrm{kg})$, E2: 7-MEGA ${ }^{\mathrm{TM}} 500$ (100 mg/kg), E3: 7-MEGA ${ }^{\mathrm{TM}} 500$ (50 mg/kg). 
(National Institutes of Health, Bethesda, MD, USA).

Statistical analysis. SPSS 17.0 software was used for all statistical analyses. Skin thickness data a and mRNA or protein expression levels were analyzed by one-way analysis of variance (ANOVA) followed by Duncan's test. Skin wrinkles and skin barrier function data were analyzed by two-way ANOVA followed by Duncan's multiple range test when appropriate. Data are expressed as mean \pm standard error (SE). Value of $p<0.05$ was considered significant for all comparisons made.

\section{RESULTS}

Determination of wrinkle grade. This in vivo study demonstrated that oral administeration of 7-MEGA ${ }^{\mathrm{TM}} 500$ alleviated the photoaging effect of UVB-radiation on skin. To investigate the effect of 7-MEGA ${ }^{\mathrm{TM}} 500$ on UVBinduced wrinkle formation, we induced skin photoaging by repeatedly exposing the skin of hairless mice to UVB for 8 weeks. The 7-MEGA ${ }^{\mathrm{TM}} 500$ was then orally administered once a day for 4 weeks. Visual analysis and replica were made at 8 weeks (before oral administration) and 12 weeks (before autopsy). The prepared replica was analyzed with a wrinkle analyzer (VisioLine, VL650, Courage-Khazaka Electronic GmbH, Cologne, Germany). We found that UVB-irradiated skin showed wrinkles. However, 7-MEGA ${ }^{\mathrm{TM}} 500$ blocked wrinkle formation (Fig. 1, Table 4). The experimental group showed a dose-dependent recovery pattern. At 12 weeks, wrinkles were weakening and skin surface was soft with elasticity. Wrinkles from in the test substance group were significantly reduced compared to those in the vehicle control (VC) group.

Measurement of skin barrier function. Results of moisture content and TEWL after treatment with 7MEGA $^{\mathrm{TM}} 500$ are shown in Table 5 . In both UVB irradiated groups, TEWL gradually increased while water content gradually decreased ( 1 to 8 weeks). From the first week after treatment with the test substance, moisture content of the skin increased dose-dependently in all groups while TEWL tended to decrease. These results strongly suggest that $7-\mathrm{MEGA}^{\mathrm{TM}} 500$ can help protect against or restore UVB irradiation-induced skin barrier

Table 4. Evaluation of wrinkles through replica analysis of hairless mouse before autopsy

\begin{tabular}{lrccccc}
\hline \hline & & NC & VC & E1 & E2 & E3 \\
\hline Wrinkle area $\left(\mathrm{mm}^{2}\right)$ & $8 \mathrm{w}$ & $19.0 \pm 10.5^{* *}$ & $50.0 \pm 7.5$ & $41.5 \pm 5.8$ & $54.0 \pm 31.1$ & $57.8 \pm 42.1$ \\
& $12 \mathrm{w}$ & $17.8 \pm 5.9^{* *}$ & $76.6 \pm 26.2$ & $19.9 \pm 9.9^{* *}$ & $33.2 \pm 10.9^{* *}$ & $35.2 \pm 43.6^{*}$ \\
No. of wrinkles & $8 \mathrm{w}$ & $52.0 \pm 14.2$ & $89.0 \pm 40.1$ & $95.0 \pm 18.4$ & $101.5 \pm 23.3$ & $91.0 \pm 7.1$ \\
& $12 \mathrm{w}$ & $46.7 \pm 25.4^{*}$ & $83.0 \pm 28.2$ & $52.0 \pm 2.8^{*}$ & $68.5 \pm 6.4$ & $67.5 \pm 12.0$ \\
Total length $(\mathrm{mm})$ & $8 \mathrm{w}$ & $38.5 \pm 3.2^{* *}$ & $97.5 \pm 8.0$ & $92.6 \pm 24.2$ & $92.5 \pm 29.92$ & $81.2 \pm 24.1$ \\
& $12 \mathrm{w}$ & $35.5 \pm 7.4^{* *}$ & $94.9 \pm 37.3$ & $30.2 \pm 10.3^{* *}$ & $38.6 \pm 4.1^{* *}$ & $49.18 \pm 8.06^{*}$ \\
Mean length $(\mathrm{mm})$ & $8 \mathrm{w}$ & $0.6 \pm 0.1^{*}$ & $0.9 \pm 0.3$ & $1.1 \pm 0.2$ & $0.9 \pm 0.1$ & $0.9 \pm 0.2$ \\
& $12 \mathrm{w}$ & $0.4 \pm 0.1^{* *}$ & $1.1 \pm 0.1$ & $0.5 \pm 0.1^{* *}$ & $0.7 \pm 0.2^{* *}$ & $0.8 \pm 0.2^{* *}$ \\
Mean depth $(\mu \mathrm{m})$ & $8 \mathrm{w}$ & $90.6 \pm 2.8^{* *}$ & $116.3 \pm 13.1$ & $103.7 \pm 8.6$ & $103.6 \pm 13.4$ & $102.4 \pm 7.0$ \\
& $12 \mathrm{w}$ & $84.2 \pm 7.1^{*}$ & $120.7 \pm 29.0$ & $69.7 \pm 14.5^{*}$ & $90.1 \pm 5.1$ & $91.7 \pm 4.1$ \\
\hline
\end{tabular}

8w: Just before oral administration, 12w: Four weeks after oral administration. NC: Normal control, VC: Vehicle control, E1: 7-MEGA ${ }^{\text {TM }} 500$ $(200 \mathrm{mg} / \mathrm{kg}), \mathrm{E} 2: 7-\mathrm{MEGA}^{\mathrm{TM}} 500(100 \mathrm{mg} / \mathrm{kg}), \mathrm{E} 3: 7-\mathrm{MEGA}^{\mathrm{TM}} 500(50 \mathrm{mg} / \mathrm{kg})$. Values are means $\pm \mathrm{SE}(\mathrm{n}=7) .{ }^{*} p<0.05,{ }^{* *} p<0.01 \mathrm{as}$ compared to the VC group by ANOVA and Duncan's multiple range test.

Table 5. Changes of trans-epidermal water loss (TEWL) and skin water content (WC) by time and group

\begin{tabular}{|c|c|c|c|c|c|c|}
\hline & & $\mathrm{NC}$ & $\mathrm{VC}$ & E1 & E2 & E3 \\
\hline \multirow[t]{2}{*}{$8 w$} & TEWL & $4.5 \pm 0.6^{* *}$ & $29.1 \pm 1.3$ & $27.3 \pm 1.2^{*}$ & $26.9 \pm 1.5^{*}$ & $28.7 \pm 1.3$ \\
\hline & WC & $78.2 \pm 2.3^{* *}$ & $25.9 \pm 2.1$ & $29.4 \pm 2.7^{*}$ & $29.7 \pm 3.1^{*}$ & $32.0 \pm 5.6^{*}$ \\
\hline \multirow[t]{2}{*}{$9 \mathrm{w}$} & TEWL & $5.6 \pm 0.5^{* *}$ & $31.5 \pm 1.4$ & $19.9 \pm 1.0^{* *}$ & $26.3 \pm 1.0^{* *}$ & $28.1 \pm 1.3^{* *}$ \\
\hline & WC & $77.3 \pm 2.1^{* *}$ & $24.7 \pm 2.2$ & $70.1 \pm 2.6^{* *}$ & $39.2 \pm 3.4^{* *}$ & $41.1 \pm 4.2^{* *}$ \\
\hline \multirow[t]{2}{*}{$10 \mathrm{w}$} & TEWL & $5.6 \pm 0.4^{* *}$ & $34.8 \pm 1.8$ & $18.9 \pm 1.2^{* *}$ & $25.0 \pm 2.2^{* *}$ & $27.4 \pm 0.6^{* *}$ \\
\hline & WC & $76.2 \pm 3.0^{* *}$ & $22.8 \pm 1.9$ & $75.6 \pm 3.0^{* *}$ & $49.6 \pm 1.0^{* *}$ & $47.0 \pm 1.5^{* *}$ \\
\hline \multirow[t]{2}{*}{$11 w$} & TEWL & $6.2 \pm 0.7^{* *}$ & $39.6 \pm 1.6$ & $17.6 \pm 1.0^{* *}$ & $23.6 \pm 2.5^{* *}$ & $26.1 \pm 0.8^{* *}$ \\
\hline & WC & $76.1 \pm 2.3^{* *}$ & $20.1 \pm 3.1$ & $77.1 \pm 2.7^{* *}$ & $56.3 \pm 1.7^{* *}$ & $48.5 \pm 0.7^{* *}$ \\
\hline \multirow[t]{2}{*}{$12 \mathrm{w}$} & TEWL & $6.2 \pm 0.6^{* *}$ & $40.2 \pm 2.0$ & $14.8 \pm 1.1^{* *}$ & $20.1 \pm 2.0^{* *}$ & $23.6 \pm 0.9^{* *}$ \\
\hline & WC & $74.1 \pm 2.4^{* *}$ & $16.1 \pm 2.2$ & $82.4 \pm 1.1^{* *}$ & $60.6 \pm 1.4^{* *}$ & $50.9 \pm 1.3^{* *}$ \\
\hline
\end{tabular}

Unit: TEWL $\left(\mathrm{g} / \mathrm{h} / \mathrm{m}^{2}\right)$, WC (AU). 8w: Just before oral administration, $9 \mathrm{w}$ to $12 \mathrm{w}$ : From one week to four weeks after oral administration. NC: Normal control, VC: Vehicle control, E1: 7-MEGA ${ }^{\mathrm{TM}} 500(200 \mathrm{mg} / \mathrm{kg})$, E2: 7-MEGA ${ }^{\mathrm{TM}} 500$ (100 mg/kg), E3: 7-MEGA 500 (50 mg/kg). Values are means $\pm \mathrm{SE}(\mathrm{n}=7) .{ }^{*} p<0.05,{ }^{* *} p<0.01$ as compared to the VC group by ANOVA and Duncan's multiple range test. 


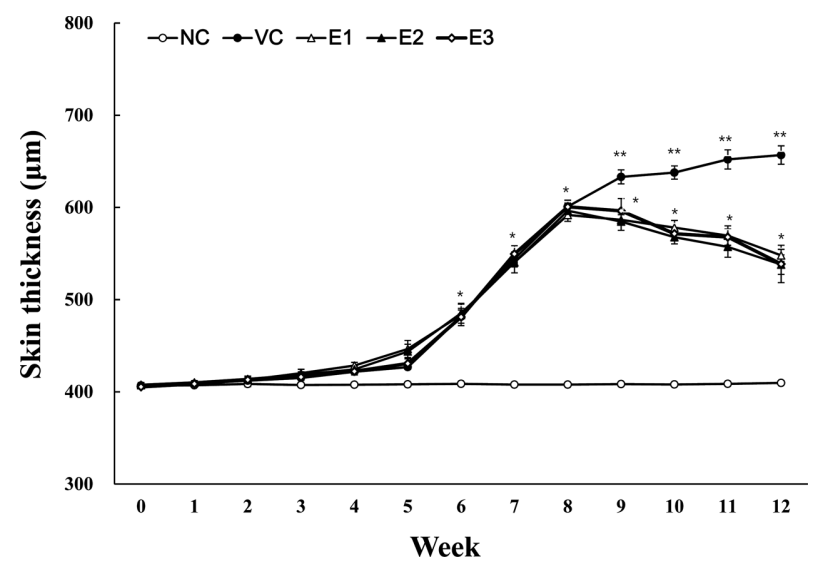

Fig. 2. Effects of the 7-MEGA ${ }^{\mathrm{TM}} 500$ on skin thickness in chronic UVB-irradiated hairless mice. NC: Normal control, VC: Vehicle control, E1: 7-MEGA ${ }^{\mathrm{TM}} 500$ (200 mg/kg), E2: 7-MEGA ${ }^{\mathrm{TM}} 500$ (100 $\mathrm{mg} / \mathrm{kg}), E 3: 7-M E G A^{\mathrm{TM}} 500(50 \mathrm{mg} / \mathrm{kg})$. Values represent the mean \pm SE $(n=7)$. *Significantly different from NC group $(p<$ $0.05)$. ${ }^{*}$ Significantly different from other groups $(p<0.05)$.

dysfunction.

Measurement of skin thickness. Skin thickness of hairless mice gradually increased after 8 weeks of UVB irradiation. However, skin thickness significantly decreased from the first week after oral administration of 7-MEGA ${ }^{\mathrm{TM}}$ 500. Such decrease was proportional to the duration of administration. These results suggest that 7-MEGA ${ }^{\mathrm{TM}} 500$ can improve skin thickness thickened by ultraviolet light (Fig. 2).

Histological observation. To investigate the effect of 7-MEGA ${ }^{\mathrm{TM}} 500$ on UV-induced photoaging in hairless mice, the thickness of epidermis was observed by $\mathrm{H} \& \mathrm{E}$ staining. Epidermal thickness was measured with a ruler at 400 magnification of microscopy. The epidermal thickness in the VC group $(31.5 \pm 0.5 \mu \mathrm{m})$ was significantly increased compared to that in the NC group $(11 \pm 0.2 \mu \mathrm{m})$ $(p<0.05)$. However, 4 weeks of intake of 7-MEGA ${ }^{\mathrm{TM}} 500$ significantly reduced the thickness of the epidermis. Such decrease was dependent on the dose of the concentration of $7-\mathrm{MEGA}^{\mathrm{TM}} 500(\mathrm{E} 1<\mathrm{E} 2<\mathrm{E} 3,15 \pm 0.3<21 \pm 0.1<$ $23 \pm 0.2 \mu \mathrm{m}$, Fig. 3). These results suggest that 7-MEGA ${ }^{\mathrm{TM}}$ 500 treatment can significantly improve the epidermal thickness of hairless mice thickened by UV irradiation.

MMP-3 and c-Jun expression. MMPs and c-Jun can be used as photo-aging markers. Our results revealed that 12 weeks of UVB irradiation significantly increased mRNA and protein levels of MMP-3 and c-Jun in dorsal skin. However, 4 weeks of 7-MEGA ${ }^{\mathrm{TM}} 500$ treatment significantly reduced MMP-1 and c-Jun expression levels in the dose-dependent manner (Fig. 4).

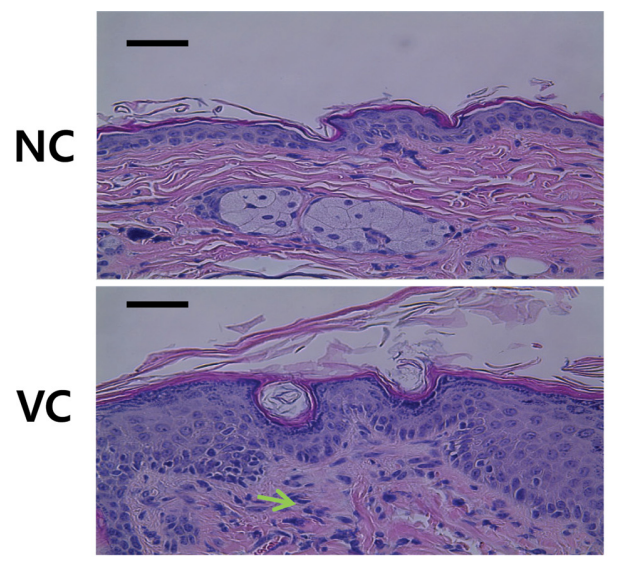

E1

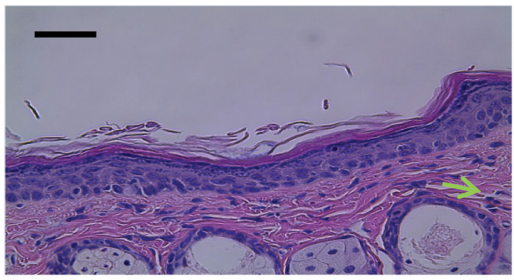

E2

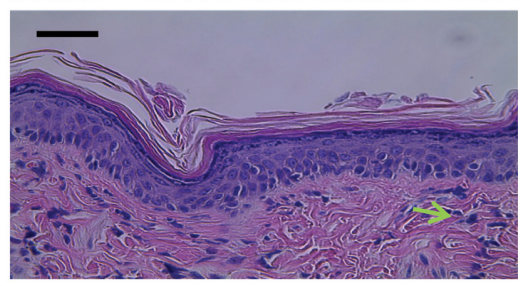

E3

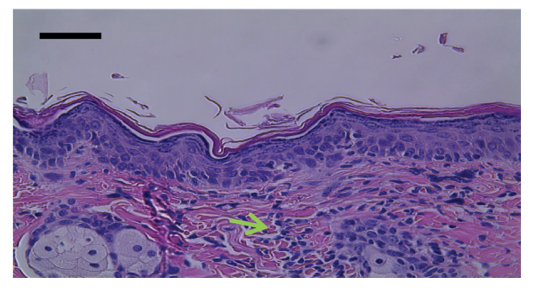

Fig. 3. Histopathological evaluation of 7-MEGA ${ }^{\mathrm{TM}} 500$ treatment on skin thickness in UVB-irradiated hairless mice. NC: Normal control, VC: Vehicle control, E1: 7-MEGA ${ }^{\mathrm{TM}} 500$ (200 $\mathrm{mg} / \mathrm{kg})$, E2: 7-MEGA ${ }^{\mathrm{TM}} 500$ (100 mg/kg), E3: 7-MEGA ${ }^{\mathrm{TM}} 500$ (50 $\mathrm{mg} / \mathrm{kg}$ ). Arrow: infiltration of inflammatory cells. bar $=20 \mu \mathrm{m}$.

\section{DISCUSSION}

UV irradiation is known as a skin photoaging factor. It causes wrinkle, roughness, relaxation, and pigmentation of skin (2). Especially, UVB irradiation causes photo-aging determined by expression of c-Jun and MMPs that can degrade the extracellular matrix (ECM). Developing c-Jun and MMPs inhibitor can be a promising strategy for photoaging therapy (15). This study suggests that 7-MEGA ${ }^{\mathrm{TM}} 500$ might be useful as a functional ingredient by observing changes in expression levels of c-Jun and MMP-3 on skin.

Effect of 7-MEGA ${ }^{\mathrm{TM}} 500$ on UVB-induced photo-aging was evaluated by determining changes in clinical sign and biomolecular markers. In photo-aging symptoms, wrinkle 

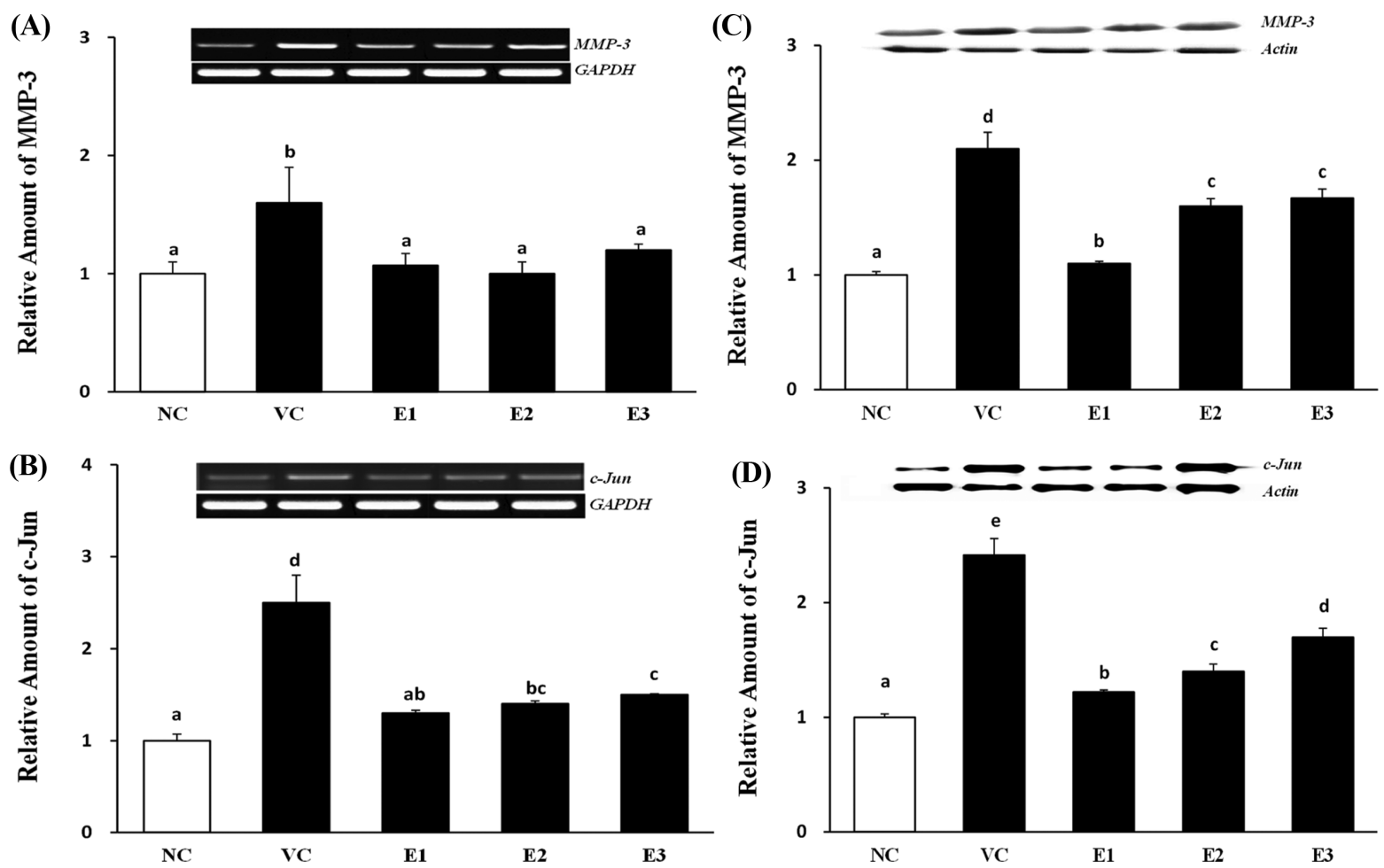

Fig. 4. Effect of the 7-MEGA ${ }^{T M} 500$ on the expression of MMP-3 and c-Jun induced by UVB in hairless mice skin. (a) MMP-3 mRNA expression level. (b) c-Jun mRNA expression level. (c) MMP-3 protein level. (d) c-Jun protein level. NC: Normal control, VC: Vehicle control, E1: 7-MEGA $500(200 \mathrm{mg} / \mathrm{kg})$, E2: 7-MEGA ${ }^{\mathrm{TM}} 500(100 \mathrm{mg} / \mathrm{kg})$, E3: 7-MEGA ${ }^{\mathrm{TM}} 500(50 \mathrm{mg} / \mathrm{kg})$. Data are expressed as the mean $\pm S E(n=7)$. Values with different letters are significantly different from each other $(p<0.05)$.

is exacerbated by increased TEWL. In this study, TEWL and wrinkle were also increased in UVB-induced photo-aging model. However, 7-MEGA ${ }^{\mathrm{TM}} 500$ treatment decreased both TEWL and wrinkles compared to VC. Water content in the group treated with 7-MEGA ${ }^{\mathrm{TM}} 500$ was increased compared to that in the VC group. Fine lines are geneally made by alteration in the surface of the skin or the epidermis whereas deep wrinkles are formed by changes in the dermis (16). Treatment with 7-MEGA ${ }^{\mathrm{TM}} 500$ visibly reduced formation of both fine lines and deep wrinkles in hairless mice.

UVB can induce photo-aging by damaging skin and inducing epidermal hyperplasia (16). Thus, measuring the thickness of irritated skin is a reliable indicator of photoaging $(17,18)$. Previous studies have reported that topical application of polyunsaturated fatty acids can attenuate UVinduced epidermal and dermal thickness in hairless mice (19), consistent with results of this study. Results of H\&E staining showed that epidermis thickness and inflammatory cell infiltration were significantly decreased in 7-MEGA ${ }^{\mathrm{TM}}$ 500 treated groups, similarly to those in the NC group. Another previous study (20) evaluated the effect of cis-palmitoleic acid supplementation on inflammatory activity and the expression of genes HNF4 $\gamma, \mathrm{HNF} 4 \alpha$ and IL6 in the colonic mucosa of patients with ulcerative colitis (UC). Cispalmitoleic acid as co-adjuvant therapy for 8 weeks seemed to decrease the inflammatory activity through the increased expression of HNF $4 \alpha$ and $\mathrm{HNF} 4 \gamma$ in patients with UC.

In this study, high levels of mRNA expression of c-Jun and MMP-3 were observed in the photo-aging model induced by UVB. c-Jun and MMP-3 mRNA expression levels were significantly lower in E1, E2, and E3 groups treated with 7-MEGA ${ }^{\mathrm{TM}} 500$ than those in the VC group. Protein expression levels of c-Jun and MMP-3 using western blot showed the same results. MMPs expression is generally low in unstimulated skin cells or normal skin tissue. However, it is significantly increased concomitant with symptoms such as epidermal hyperplasia and skin wrinkles in hairless mice chronically exposed to ultraviolet (21). In addition, c-Jun is a nuclear protein that is not expressed or expressed very low in normal skin tissue. However, it is rapidly increased by UV stimulation (22). Previous studies have shown that overexpression of c-Jun can reduce the expression of type I collagen (23).

Results of this study suggest that 7-MEGA ${ }^{\mathrm{TM}} 500$ could be effective in preventing and treating photo-aging by altering various indices related to photo-aging induced by UVB. However, further studies are needed to understand which components of 7-MEGA ${ }^{\mathrm{TM}} 500$ are directly responsible for the improvement of photo-aging. In conclusion, results of this study indicate that $7-\mathrm{MEGA}^{\mathrm{TM}} 500$ could 
help recover photo-aging induced by UVB. Thus, 7MEGA $^{\mathrm{TM}} 500$ might be useful as a functional raw material to improve skin photo-aging.

\section{ACKNOWLEDGMENTS}

This research was supported by the collaborative R\&BD program (2017) of Agency for Korea National Food Cluster (AnFC).

\section{CONFLICT OF INTEREST}

The authors have no conflict of interest to disclose.

Received March 4, 2019; Revised April 1, 2019; Accepted April 25, 2019

\section{REFERENCES}

1. Kim, H.H., Cho, S., Lee, S., Kim, K.H., Cho, K.H., Eun, H.C. and Chung, J.H. (2006) Photoprotective and anti-skinaging effects of eicosapentaenoic acid in human skin in vivo. J. Lipid Res., 47, 921-930.

2. Kim, H.H., Lee, M.J., Lee, S.R., Kim, K.H., Cho, K.H., Eun, H.C. and Chung, J.H. (2005) Augmentation of UV-induced skin wrinkling by infrared irradiation in hairless mice. Mech. Ageing Dev., 126, 1170-1177.

3. Storey, A., McArdle, F., Friedmann, P.S., Jackson, M.J. and Rhodes, L.E. (2005) Eicosapentaenoic acid and docosahexaenoic acid reduce UVB- and TNF-alpha-induced IL-8 secretion in keratinocytes and UVB-induced IL-8 in fibroblasts. J. Invest. Dermatol., 124, 248-255.

4. Jo, W.S., Yang, K.M., Park, H.S., Kim, G.Y., Nam, B.H., Jeong, M.H. and Choi, Y.J. (2012) Effect of microalgal extracts of tetraselmissuecica against UVB-induced photoaging in human skin fibroblast. Toxicol. Res., 28, 241-248.

5. Otton, R., Marin, D.P., Bolin, A.P., Macedo, R.D.C.S., Campoio, T.R., Fineto, C., Jr., Guerra, B.A., Leite, J.R., Barros, M.P. and Mattei, R. (2012) Combined fish oil and astaxanthin supplementation modulates rat lymphocyte function. Eur. J. Nutr., 51, 707-718.

6. Calder, P.C. (2008) Polyunsaturated fatty acids, inflammatory processes and inflammatory bowel diseases. Mol. Nutr. Food Res., 52, 885-897.

7. Bazan, N.G. (2007) Omega-3 fatty acids, pro-inflammatory signaling and neuroprotection. Curr. Opin. Clin. Nutr. Metab. Care, 10, 136-141.

8. Park, J.M., Kwon, S.H., Han, Y.M., Hahm, K.B. and Kim, E.H. (2013) Omega-3 polyunsaturated Fatty acids as potential chemopreventive agent for gastrointestinal cancer. $J$. Cancer Prev., 18, 201-208.

9. Whigham, L.D., Watras, A.C. and Schoeller, D.A. (2007) Efficacy of conjugated linoleic acid for reducing fat mass: a meta-analysis in humans. Am. J. Clin. Nutr., 85, 1203-1211.

10. Finucane, O.M., Lyons, C.L., Murphy, A.M., Reynolds, C.M., Klinger, R., Healy, N.P., Cooke, A.A., Coll, R.C., McAllan, L., Nilaweera, K.N., O’Reilly, M.E., Tierney, A.C., Morine,
M.J., Alcala-Diaz, J.F., Lopez-Miranda, J., O’Connor, D.P., O’Neill, L.A., McGillicuddy, F.C. and Roche, H.M. (2015) Monounsaturated fatty acid-enriched high-fat diets impede adipose NLRP3 inflammasome-mediated IL-1 $\beta$ secretion and insulin resistance despite obesity. Diabetes, 64, 2116-2128.

11. Nicolai, E., Sinibaldi, F., Sannino, G., Laganà, G., Basoli, F., Licoccia, S., Cozza, P., Santucci, R. and Piro, M.C. (2017) Omega- 3 and Omega- 6 fatty acids act as inhibitors of the matrix metalloproteinase- 2 and matrix metalloproteinase-9 activity. Protein J., 36, 278-285.

12. Zielińska, A. and Nowak, I. (2017) Abundance of active ingredients in sea-buckthorn oil. Lipids Health Dis., 16, 95.

13. Maguire, L.S., O'Sullivan, S.M., Galvin, K., O'Connor, T.P. and O'Brien, N.M. (2004) Fatty acid profile, tocopherol, squalene and phytosterol content of walnuts, almonds, peanuts, hazelnuts and the macadamia nut. Int. J. Food Sci. Nutr., 55, 171-178.

14. Song, I.B., Gu, H., Han, H.J., Lee, N.Y., Cha, J.Y., Son, Y.K. and Kwon, J. (2018) Effects of 7-MEGA ${ }^{\mathrm{TM}} 500$ on oxidative stress, inflammation, and skin regeneration in $\mathrm{H}_{2} \mathrm{O}_{2}$ treated skin cells. Toxicol. Res., 34, 103-110.

15. Moon, H.J., Lee, S.R., Shim, S.N., Jeong, S.H., Stonik, V.A., Rasskazov, V.A., Zvyagintseva, T. and Lee, Y.H. (2008) Fucoidan inhibits UVB-induced MMP-1 expression in human skin fibroblasts. Biol. Pharm. Bull., 31, 284-289.

16. Sirerol, J.A., Feddi, F., Mena, S., Rodriguez, M.L., Sirera, P., Aupí, M., Perez, S., Asensi, M., Ortega, A. and Estrela, J.M. (2015) Topical treatment with pterostilbene, a natural phytoalexin, effectively protects hairless mice against UVB radiation-induced skin damage and carcinogenesis. Free Radic. Biol. Med., 85, 1-11.

17. Saw, C.L., Huang, M.T., Liu, Y., Khor, T.O., Conney, A.H. and Kong, A.N. (2011) Impact of Nrf2 on UVB-induced skin inflammation/photoprotection and photoprotective effect of sulforaphane. Mol. Carcinog., 50, 479-486.

18. Huang, M.T. (2006) Inhibitory effects of black tea theaflavin derivatives on 12-O-tetradecanoylphorbol-13-acetateinduced inflammation and arachidonic acid metabolism in mouse ears. Mol. Nutr. Food Res., 50, 115-122.

19. Jin, X.J., Kim, E.J., Oh, I.K., Kim, Y.K., Park, C.H. and Chung, J.H. (2010) Prevention of UV-induced skin damages by $11,14,17-$ eicosatrienoic acid in hairless mice in vivo. $J$. Korean Med. Sci., 25, 930-937.

20. Bueno-Hernández, N., Sixtos-Alonso, M.S., MilkeGarcía, M.D.P. and Yamamoto-Furusho, J.K. (2017) Effect of Cispalmitoleic acid supplementation on inflammation and expression of HNF4 $\gamma, \mathrm{HNF} 4 \alpha$ and IL6 in patients with ulcerative colitis. Minerva Gastroenterol. Dietol., 63, 257-263.

21. Hunt, D.P., Jaholda, C. and Chandran, S. (2009) Multipotent skin-derived precursors: from biology to clinical translation. Curr. Opin. Biotechnol., 20, 522-530.

22. Quan, T.H., Qin, Z.P., Xu, Y.R., He, T., Kang, S., Voorhees, J.J. and Fisher, G.J. (2010) Ultraviolet irradiation induces CYR61/CCN1, a mediator of collagen homeostasis, through activation of transcription factor AP-1 in human skin fibroblasts. J. Invest. Dermatol., 130, 1697-1706.

23. Guo, B.R., Liu, P. and Ma, C.C. (2009) The expression of cjun, c-fos in light aging disease and significance. Chin. Skin Venereol. Mag., 23, 791-793. 